DOI: $10.14451 / 2.138 .25$

\title{
ФИНТЕХ В ЦИФРОВИЗАЦИИ ЭЛЕКТРОННЫХ ТОВАРОРАСПОРЯДИТЕЛЬНЫХ ДОКУМЕНТОВ
}

\author{
(c) 2019 Папаскуа Гиви Тенгизович \\ аспирант, кафедра финансового права \\ Московский государственный юридический университет, Россия, Москва \\ E-mail: Givipapaskua@gmail.com
}

Появление технологии блокчейн позволяет в будущем отказаться от коносаментов в их бумажном оформлении. В настоящее время несколько морских хабов, включая Сингапур, изучают возможность цифровизации торговой и морской документации, такой как коносаменты, с использованием технологии блокчейн. Однако сохраняется значительная неопределенность в отношении юридической состоятельности коносаментов блокчейн, как и других электронных документов. В статье рассматриваются основания и возможности использования электронных коносаментов в модели распространенного реестра, а также препятствия к их применению в юрисдикциях общего права. Принятие MLETR" может обеспечить правовой режим для блокчейн-коносаментов. Рассматриваются ключевые положения MLETR, в результате чего предлагаются варианты поправок модельного правового акта. Рассматриваемые подходы в правовом регулировании подготовят соответствующие юрисдикции общего права к новой технологической эпохе в судоходной отрасли.

Ключевые слова: коносамент, блокчейн, оборотоспособность, токен, электронный реестр.

Типовой закон «Об электронных переводных документах» (MLETR) направлен на обеспечение легального использования электронных переводных документов как внутри страны, так и за рубежом. MLETR применяется к электронным переводным регистровым записям, которые функционально эквивалентны переводным документам или инструментам. Переводные документы или инструменты - это бумажные документы или инструменты, которые дают владельцу право требовать исполнения указанного в них обязательства и которые позволяют передать требование к этому исполнению путем передачи владения документом. К переводным документам или инструментам обычно относятся коносаменты, переводные векселя, векселя и складские расписки.

Трансфорабельность и доступность в электронном виде документов может быть весьма полезна для облегчения электронной торговли, например, за счет повышения скорости и безопасности передачи, разрешения повторного использования данных и автоматизации некоторых транзакций с помощью «смартконтрактов» ${ }^{* * *}$.

MLETR основывается на принципах недискриминации в отношении использования электронных средств, функциональной эквивалентности и технологической нейтральности, лежащих в основе всех текстов ЮНСИТРАЛ по электронной торговле. Поэтому он может предусматривать использование всех технологий и всех моделей, таких как реестры, токены и распределенные бухгалтерские регистры.

Со времен позднего средневековья перевозчиками оформлялись бумажные документы на товары, отгружаемые на борту торговых судов. Эта практика приобрела сложный характер: от выдачи бумажных квитанций и регистрации груза на борту судна в регистре пергаментной книги **** до выпуска элементарных вариантов бумажных коносаментов, подтверждающих полу-

\footnotetext{
* UNCITRAL Model Law on Electronic Transferable Records (“MLETR”) является модельной правовой формой, принятой Комиссией ООН в отношении права международной торговли (UNCITRAL) в 2017.

** См.: Elson Ong. Blockchain bills of lading CML Working Paper Series, No 17/01, March 2017, http://law.nus.edu.sg/ cml/wps.html (обращение 20.06.2019).

*** Статья 16 Ordinamenta et Consuetudo Maris de Trani от 1063 года обязывала каждого судоводителя брать с собой клерка, который был бы обязан дать клятву верности и вести учет товаров, полученных от грузоотправителя в своем реестре, покрытом пергаментом: Сэр Трэверс Твисс (Travers Twiss (ed)), Черная книга Адмиралтейства, том 4 (Longman \& Co 1876) 533-535 (Twiss T. The Black Book of the Admiralty. Vol. I.- L.: Longman \& Co., 1871. (reprinted in 1998 by the Lawbook Exchange).
} 
чение, а затем содержащих договорные положения. Эти квитанции в конечном итоге приняли более сложные свойства, такие как оборотоспособность. Сегодня бумажные коносаменты повсеместно распространены в международной торговле.

Вместе с тем, существует множество проблем использования указанных коммерческих документов: их подделка, выдача обманным путем и пр. Однако это тот риск, на который согласились трейдеры, в обмен на скорость и удобство использования подобных документов. Кроме того, для доставки бумажных коносаментов в порт назначения требуется время. Уже нет уверенности в том, что первоначальные бумажные коносаменты будут доставляться получателю или индорсиденту до прибытия груза в порт назначения. Эволюция морских перевозок с судов, приводимых в движение парусом, и, позднее, моторных судов привела к ускорению морских перевозок. Торговля может быть связана с документарным кредитом, требующим от коносамента оформление в банке, увеличивая время его выдачи и обращения. В некоторых сделках может быть несколько перепродаж в коротких рейсах, что приводит к дополнительной документарной нагрузке, а также увеличению времени передачи. Несвоевременное прибытие коносаментов может также быть причиной перегруженности портов в связи с тем, что получатель (приемники) груза не имеют первоначального коносамента для представления для доставки груза. В ситуациях, когда доставка товаров осуществляется без производства коносаментов, существует хорошо развитая отраслевая практика доставки грузов по гарантийным письмам вместо оригинальных коносаментов. Однако это ставит продавца в сложное положение, заключающееся в том, что он не может оплатить очистку груза, и может привести к затяжному судебному разбирательству.

Практические ограничения, связанные с бумажными коносаментами, могут быть устранены с помощью технологического решения, такого как использование электронных методов для выдачи коносаментов в электронной форме. Это не только предотвратит возникновение фиктивных и мошеннических коносаментов, но и приведет к мгновенной передаче коносамента. На протяжении ряда лет существуют электронные коносаменты с общедоступными электронными платформами, однако они не получили широ- кого распространения из-за неопределенности в отношении юридического основания их использования. Эта неопределенность может быть объяснена отсутствием правовой инфраструктуры для поддержки использования электронного коносамента, противоречивым модельным подходом к регистру, заключающимся в идентификации держателя электронного коносамента, и отсутствием подходящей технологии для облегчения подхода, основанного на модели токенов.

В настоящее время необходимо разработать международную систему правового регулирования деловых отношений в сфере коммерческого судоходства. Основание такой правовой базы должно являться соглашение о использовании электронных коносаментов, использование электронных систем регистрации; пользователи таких систем соглашаются с договорными условиями, установленными коммерческими поставщиками, до получения доступа к реестру. Третьи стороны не имеют доступа к сети договоров, заключаемых коммерческими провайдерами и пользователями их систем.

Модель реестра идентифицирует контролируемое лицо в отдельном независимом реестре третьей стороны. Это требует тщательного контроля за реестром и системы проверки целостности электронной передаваемой записи (ETR), с тем чтобы надежно установить ее владельца. Создание, выдача и передача ETR основаны на информации, передаваемой в центральный реестр и регистрируемой в нем, причем концепция контроля и связанные с этим вопросы безопасности сосредоточены на реестре, а не на самой ЕТР.

ETR в модели реестра не существует в цифровой форме как токен для торговли. Вместо этого ETR просто содержит ссылку на реестр, в котором можно найти личность контролирующего лица. Однако ссылка не ведет себя как символический ключ от склада и поэтому не может находится в традиционном правовом владении. Как таковая, модель реестра неизменно использует подход управления для идентификации держателя. Это включает идентификацию лица, имеющего право осуществлять права, закрепленные в ЕТР, путем идентификации лица, контролирующего ЕTP.

Для того чтобы придать законную силу электронным коносаментам в соответствии с моделью регистрации, преобладающее решение предусматривает, что контроль над ETR имеет те 
же последствия, что и обладание бумажным коносаментом. Это решение было принято рядом правовых режимов, таких, как Международные правила морского судоходства для электронных коносаментов (Comite Maritime International Rules for Electronic Bills of Lading), Роттердамскими правилами и недавно Типовой закон ЮНСИТРАЛ об электронных передаваемых записях (UNCITRAL Model Law on Electronic Transferable Records (MLETR)).

В настоящее время модель реестра несовместима с передаваемыми документами, она не обеспечивает оборотоспособность бездокументарного актива, поскольку эта модель не допускает ни акта доставки, ни актов индоссамента и доставки. Передача контроля над электронной записью между двумя сторонами в реестре, как представляется, лишь приводит к изменению лица, контролирующего электронную запись, вместо передачи электронной записи от одной стороны другой стороне, которая передала бы посессорные и договорные права. Из этого следует, что лицо, получающее контроль над электронным коносаментом в соответствии с моделью регистрации, не может ни получить доступ к посессорным правам коносамента на требование о сдаче груза в порту разгрузки, ни обратиться за договорными средствами правовой защиты, вытекающими из нарушения договора перевозки.

Можно заметить, что системы реестров более точно отражают практику регистрации грузов на борту судов в книгах учета пергамента одиннадцатого века, чем современные коносаменты. Как отметила ЮНСИТРАЛ, права в товарах, представленных правоустанавливающими документами, обычно обусловлены физическим владением оригинальным бумажным документом, таким, как коносамент, складская квитанция или другой аналогичный документ. Электронный коносамент в соответствии с регистрационной моделью представляет права в товарах путем контроля регистрационной записи, и именно по этой причине электронные коносаменты, как представляется, представляют собой просто бухгалтерские книги.

Существует реальная опасность того, что принятие регистрационной модели обратит вспять несколько столетий прогресса, регрессируя к средневековым коносаментам. В стремлении придать электронному коносаменту тот же уровень правового признания, что и бумажно- му коносаменту, предполагалось, что техника удержания ЕТР будет основываться на основных целях и функциях первичного бумажного коносамента. Однако сама причина контрольного подхода заключалась в том, что обладание электронной записью до появления технологии блокчейн было не способно к тиражированию. Кроме того, Четвертая рабочая группа ЮНСИTРАЛ вновь заявила, что MLETR не будет заниматься вопросами, регулируемыми материальным правом. Однако контрольный подход может непреднамеренно нарушить существующие правовые концепции и подходы, лежащие в основе первичных требований к бумажному коносаменту, которых ЮНСИТРАЛ стремилась избежать.

Модель токена идентифицирует держателя электронной передаваемой записи (ETR) в самой ETR. Она опирается на тщательный контроль над самой записью ETR. Передача процесса контроля для и идентификация владельца ETR зависит от самой программы и ее безопасности как с технической точки зрения, так и с позиций защищенности. В системе блокчейна это частично достигается путем установления технологических гарантий и гарантий безопасности существованием уникального экземпляра, который не может быть изменен, а также высокой степенью распространения данных.

Описывая ETR через токен моделирование исследователь сталкивается с проблемой терминологической определенности. Единого, тем более легального, определения токена не встретишь. Токены работают как акции, деньги в криптовалютах, баллы лояльности на карте какого-то магазина - в любом случае, токен рассматривается как некоторая ценность. В ETR сама запись, идентифицируемая как коносамент может идентифицироваться через токен.

Существуют опасения, что гипертокенизация сервисов столкнется с техническими проблемами, которые приведут к провалу и сбоям. Уже в реализации «закона Яровой» указывалось на проблемы хранения огромного объема данных. Кроме того, рост токенизации экономики требует ее переосмысление с позиций современного финансового кризиса и декларации исчерпания возможностей либерального подхода в регулировании.

Следует также преодолеть иные препятствия, связанные с отсутствием правового регулирования, идентификации ETR как бездокументарной 
ценной бумаги или иного объекта, вовлечение в систему ETR рядового гражданина, обеспеченности доступности и пр.

До появления технологии блокчейн не было подходящей технологии, которая могла бы идентифицировать держателя ETR в самой ETR. Традиционные технологии, такие как цифровые идентификаторы объектов и управление цифровыми правами, могут гарантировать, что электронные записи являются уникальными, но эти записи не могут быть переданы как уникальные маркеры. Традиционные технологические ме- тоды могли бы обеспечить безопасную передачу электронных записей в качестве токенов, но не могли обеспечить уникальность самой записи. Таким образом, электронный коносамент может существовать в виде цепочки цифровых подписей, причем передача электронного коносамента осуществляется путем хеширования электронного коносамента передающего лица и открытого ключа получающего лица и подписания электронного коносамента получателем в цифровой форме с использованием закрытого ключа передающего лица.

\section{Библиографический список}

1. Elson Ong. Blockchain bills of lading CML Working Paper Series, No 17/01, March 2017, http://law.nus.edu.sg/cml/ wps.html (обращение 20.06.2019).

2. Twiss T. The Black Book of the Admiralty. Vol. I. - L.: Longman \& Co., 1871. (reprinted in 1998 by the Lawbook Exchange).

3. UNCITRAL Model Law on Electronic Transferable Records (“MLETR”). 2017. https://www.uncitral.org/pdf/english/ texts/electcom/MLETR_ebook.pdf. (обращение 20.06.2019). 